\title{
El nuevo modelo de convivencia urbana: los enclaves habitacionales auto-segregados en Managua
}

\section{The new urban cohabitation model: self-segregated housing enclaves in Managua}

\author{
Gutiérrez Lanza, Danna ${ }^{1}$ \\ ${ }^{1}$ Profesional Independiente, asociada al Sistema de Naciones Unidad, Docente horario en Universidad \\ Centroamericana, Managua, Nicaragua \\ 1dmgutierrez29@gmail.com / https://orcid.org/0000-0003-3090-7853
}

RESUMEN | La investigación urbana en Latinoamérica ha identificado la existencia de nuevos modelos del espacio urbano en las ciudades de la región. Este modelo representa cambios en el patrón de segregación espacial, que en términos socio-habitacionales (o urbano-habitacional) implica que, aunque los grupos se encuentran en mayor proximidad física, están separados por muros o tecnologías de seguridad. En Managua el modelo de crecimiento urbano ha seguido una lógica de dispersión de baja densidad que se expande hacia las áreas suburbanas. El patrón muestra una expansión a lo largo de los ejes viales radiales convertidos en ejes importantes de inversión para desarrollos habitacionales con un carácter muy marcado: las viviendas de la "clase alta" (Rodgers, 2006). El fenómeno de la segregación espacial toma mayor fuerza a partir de la década de 1990 y hoy una serie de proyectos habitacionales que se caracterizan por su carácter segregativo acentúan el proceso de urbanización "desordenado, discontinuo y desigual" (López, 2016, p.28). Seguridad, control, gestión, son los aspectos más importantes sobre los cuales se perciben diferencias de estos espacios habitacionales en relación a la experiencia en la ciudad abierta, y por tanto se han convertido - tanto en su expresión físico-espacial, como en la social - en objeto de una evaluación diferencial, que deviene en una diferenciación de la experiencia urbana-habitacional.

PALABRAS CLAVE | Segregación urbana, Urbanizaciones Cerradas, Managua

ABSTRACT | Urban research in Latin America has identified the existence of new models of urban space in cities of the region. This model represents changes in the spatial segregation pattern, that in housing terms (socially and urbanistic) imply that, although different groups are in closer physical proximity they are separated by walls or security technologies. In Managua the urban growth model has followed a low-density dispersion logic that expands to suburban areas. The current pattern shows and urban growth alongside radial highways that become important axes for investment on housing development projects that have a very marked characteristic: houses for the "upper class" (Rodgers, 2006). Spatial segregation phenomenon takes force since 1990, and today a series of housing projects distinguished by their segregated character accentuate an urbanization process that in Managua has been "disordered, discontinuous and unequal" (López, 2016, p. 28). Safety, control and management are the most important aspects through which these housing spaces are perceived as different in relation to the experience in 
the "open city" y therefore have become - as much in their physical and spatial expression as in their social dimension - an object of a differential evaluation of the urban and housing experience. Any activity that was written down was evaluated to know what activity was most frequently. In addition, was identified the method with most activities, as a result was made a proposal of method rehabilitation and building conservation. ${ }^{1}$

KEYWORD | Urban segregation, Managua

\section{Introducción}

\section{El fenómeno de la segregación residencial}

Michael Janoschka es sin duda uno de los referentes más importantes en la temática de las urbanizaciones cerradas. Es relevante de su trabajo el análisis de orden deductivo, que arranca con el estudio del fenómeno de la división social del espacio y la segregación urbana en las ciudades latinoamericanas como fenómenos de orden más macro. A partir del cual desarrolla estudios de casos sobre los enclaves habitacionales como componentes del 'nuevo modelo de ciudad' (2002). Proceso que otros autores describen en la particularidad de lo habitacional como "(...) la formación de áreas residenciales de alto prestigio, donde viven grupos de altos ingresos que conforman un hábitat de alta calidad y valoración" (Formiga, 2000, pp.32-33).

Entre las características de este nuevo modelo van a destacar, en el nivel de la acción del individuo: la búsqueda de organización privada, en el entendido que los espacios de esta naturaleza proveen de manera más eficiente servicios (infraestructura y equipamientos); y la búsqueda de entornos más homogéneos, en términos sociales, y de un determinado estilo de vida. De igual forma, va a hacer un análisis en búsqueda de las causas más estructurales de los procesos de fragmentación espacial urbana, señalando así el rol que juegan distintos procesos de transformación económica y política; aunque el análisis de este último se encuentra fuera de los alcances de esta investigación, es importante reconocer su relevancia en el fenómeno.

Con Janoschka coinciden otros autores de la región como Caldeira (2000), citada en Roitman (2010), identificando la existencia de nuevos modelos del espacio urbano en las ciudades latinoamericanas. Este modelo representa cambios en el patrón de segregación espacial, que en términos socio-habitacionales (o urbano-habitacional) implica que, aunque los grupos se encuentran en mayor proximidad física, están separados por muros o tecnologías de seguridad. Así mismo, los espacios de circulación compartida y de interacción se han reducido. Este grupo de autores, y en general gran parte de la literatura sobre este tema, parecen acordar que el fenómeno de los enclaves urbanos cambia la escala de la segregación urbana, y que, a partir de su particularidad habitacional, aúnan a los procesos de fragmentación urbana (entendiéndola como una ruptura más que sólo una división) del tejido urbano y social, presentándose así una "intensificación de las desigualdades sociales en escala reducida" (Janoschka, 2002, p.14).

De igual forma, los autores coinciden en que la novedad del modelo no sólo está en el cambio de escala que representa, sino en que ahora, en las ciudades, "la división y desintegración social

1 Este artículo presenta uno de los capítulos de resultados de la tesis inédita de pregrado "El nuevo modelo de convivencia urbana: los enclaves habitacionales auto-segregados en Managua”, presentada para obtener la licenciatura en Sociología, de la Universidad Centroamericana UCA, Nicaragua en el año 2020 
se expresa mediante barreras físicas y limitaciones en los accesos" (Janoschka, 2002, p.15). El fenómeno no es nuevo pues se puede rastrear la división social del espacio urbano desde la aparición de las ciudades como asentamientos humanos, sin embargo, como plantea Roitman (2003) lo novedoso de la segregación urbana hoy “es su intensidad, visibilidad y explicitud” (p.7). Esta modalidad es hecha explicita a través de mecanismos de control y seguridad y barreras físicas (Roitman 2003, 2004; Janoschka 2002; Janoschka y Glasze, 2003) que marcan límites en los espacios de la ciudad, impiden la libre circulación en y a través de ellos y crean enclaves disociados del espacio urbano público.

Las urbanizaciones cerradas que, Duhau y Giglia (2016) han denominado como "formas emergentes" de la nueva división social del espacio en las ciudades latinoamericanas, son de interés para esta investigación por su valor propio como modalidad socioespacial y habitacional, y también para pensar posteriormente en la articulación del análisis de los componentes urbanos, que tome en cuenta la particularidad de cada espacio, tal como lo plantean los autores.

Este artículo presenta los resultados de la investigación centrada en el análisis del fenómeno de la segregación urbana-habitacional que toma forma en los enclaves residenciales auto-segregados como modelo de vivienda en la ciudad de Managua. Se inicia con la descripción de la metodología aplicada durante el proceso de recolección de información y del análisis de los resultados como marco para el desarrollo de los acápites siguientes. La presentación de los resultados se divide en dos; un primer apartado que da cuenta de un recorrido breve de los trabajos más relevantes sobre segregación en Managua, que nos permite entender el fenómeno en términos más generales para luego encuadrar la particularidad del modelo habitacional en el patrón de segregación de la ciudad.

Los resultados de la investigación empírica son el segundo apartado de resultados, e inician con una delimitación del marco de interpretación teórica que da forma al análisis que se presenta en el acápite de conclusiones. Estos parten de la afirmación que hace Espino (2008), basándose en los planteamientos de Dumont, sobre cómo esta tendencia a la segregación autoimpuesta y los fenómenos de este tipo dan cuenta de cómo "la estructura de la estratificación social se impone siempre desde arriba" (p.38). De ahí, que el análisis de estos temas cobre relevancia al preguntarnos sobre el desarrollo de las ciudades, en este caso Managua, y de las relaciones que pueden existir entre los espacios que aparentan no conectarse en este orden urbano fragmentado. Para cerrar, este artículo postula posibles discusiones más allá de los resultados obtenidos, como pauta para el desarrollo de futuras investigaciones.

\section{Metodología}

Esta investigación es de tipo cualitativo, de alcance exploratorio y corte transversal. El trabajo se orientó por un diseño fenomenológico, que, desde una perspectiva sociológica, busca entender la construcción de la realidad a partir de cómo la gente piensa, en simultaneidad con la interacción social (Cortéz, 2016). Esta perspectiva permite poner el énfasis en las percepciones de la personaen este caso específico en las percepciones valorativas de la experiencia- mostrando el énfasis en la vinculación entre los sujetos y su mundo, "la cual aparece en el contexto de las relaciones con objetos, personas, sucesos y situaciones" (Álvarez-Gayou, 2003, p.86), tanto como con el espacio.

Tal como lo plantea Álvarez-Gayou (2003) la fenomenología "se caracteriza por centrarse en la experiencia personal (...) y descansa en cuatro conceptos clave: la temporalidad (el tiempo vivido), la espacialidad (el espacio vivido), la corporalidad (el cuerpo vivido) y la relacionalidad 
o la comunalidad (la relación humana vivida)" (pp. 85-86). Para el fenómeno en estudio, la aproximación resulta pertinente, y se inscribe en el marco de la corriente de procedimientos cualitativos, que como explica Formiga (2000) se orienta a obtener información acerca de

la historia profesional y residencial, las prácticas y estrategias asociadas al espacio público, el acceso a la información, las imágenes personales y colectivas del espacio y la forma en que inciden estas representaciones en las relaciones entre los grupos, así como en el mercado inmobiliario, a través de la valorización y desvalorización de áreas (p.35).

Este trabajo tiene como ámbito de análisis los enclaves urbano-habitacionales, considerando a cada familia como la unidad básica de análisis; y se centró en comprender esos patrones y esas lógicas sociales del habitar. Por ello, las fuentes de información para el análisis han sido en su totalidad fuentes primarias, sólo haciendo uso de posibles fuentes documentales con fines de referencia analítica sobre el fenómeno en la región y las dinámicas de los procesos urbanos en Managua.

\section{El caso de Managua}

Sin lugar a dudas la experiencia ligada a los espacios habitacionales adquiere una relevancia particular en el conjunto de experiencias de la vida social dentro de las cuales nos desarrollamos. El modelo urbano-habitacional en el que se centra este trabajo posee una serie de particularidades que hacen de él el espacio de una práctica diferenciada, que se compone de una serie de acciones y discursos referentes al uso y apropiación de los espacios habitacionales, al igual que de los espacios comunitarios privados que comparten.

Uno de los trabajos más importantes respecto a la segregación en Managua es la investigación realizada por el inglés Dennis Rodgers (1996-97 y 2002), que se propone un análisis del desarrollo de la segregación social que ha experimentado la ciudad, identificando el autor "un nuevo patrón de segregación espacial vinculado al surgimiento de la inseguridad" (p.8). Del trabajo de Rodgers es importante destacar algunos puntos fundamentales del análisis socioespacial con los que podemos estar de acuerdo, sin embargo, es prudente tomar distancia - considerando los cambios en la dinámica del mercado inmobiliario y la apertura de los sistemas crediticios desde el año de publicación de su investigación - sobre su definición de los habitantes y usuarios de estos espacios como las "élites urbanas de la ciudad", sobre lo han desarrollado otros trabajos más recientes, y que se expondrán de manera breve más adelante. Rodgers (2006) señala que ha tenido lugar en la ciudad

[...] un proceso más ponderado de intervención a favor de las elites urbanas, que no ha buscado simplemente sobre imponer una nueva forma urbana sobre las del pasado, sino reestructura activamente el perfil global de la ciudad mediante la separación explícita de ciertos espacios urbanos (p.11).

Para este autor la transformación desigual de la ciudad se torna más evidente a través de una serie de intervenciones o proyectos urbanos a gran escala que tuvieron lugar en la ciudad durante la década de los 90 e inicios del 2000, en lo que él propone entender cómo "un patrón que sugiere una construcción o reconstrucción bastante selectiva" (2006, p.17). De esta manera, aunque para Rodgers la élite urbana en Managua tenía poco peso relativo en términos numéricos, y en los años que tuvo lugar su investigación esto implicaba poca rentabilidad para los proyectos de barrios cerrados, destaca de manera relevante la aparición de locales y servicios pensados para este grupo 
de la población, que incluyó la construcción de grandes centros comerciales y la aparición de cadenas internacionales de comida. Así, en Managua se comienza a constituir "un archipiélago de enclaves fortificados" conformado por las zonas de residencia de la élite urbana, los puntos de servicio u ocio, que, por su dispersión en el ámbito espacial de la ciudad, hicieron necesaria una red al servicio de la conexión de estos espacios, para otorgar la misma 'seguridad' de las estancias fortificadas a las rutas de desplazamiento.

Según este autor, entonces, lo que hace particular el caso de Managua no sólo es la sobreposición espacial de formas antiguas con usos o esquemas nuevos, característica para la cual rescata de Harvey (1990) el término "palimpsesto". Aún más importante, desde su análisis, es la dinámica de "desimbricación" para describir el proceso que experimenta la ciudad. Frente a lo que pudiéramos denominar las "ciudades abiertas", las cuales constituyen "sitios primordiales de imbricación territorial que (...) moldean de manera fundamental las formas por las cuales viven los actores sociales dentro de su ámbito" (Rodgers, 2006, p.20), el sistema de enclaves fortificados de Managua se extiende por el espacio físico y desconecta, tanto los lugares específicos como el sistema de calles, dando lugar a una forma urbana y social que ya no tiene relación con su contexto territorial en el sentido más amplio.

Aunque el análisis de Rodgers no se centra en la segregación o en los enclaves de carácter habitacional su trabajo es fundamental como punto de partida para las investigaciones sobre esta temática. Para él los enclaves - tanto en Managua como en el resto de América Latina - "cambian el carácter del espacio público y de la vida pública e imponen reglas de inclusión y exclusión" (p.16), un postulado que aplica también para los espacios de carácter residencial en su relación con el resto de la ciudad.

Sánchez (2017) en uno de los estudios más recientes respecto al fenómeno de la segregación urbana en la ciudad de Managua, centra su análisis en la dimensión socio-económica del fenómeno y su metodología cuantitativa - que se basa en datos censales disponibles sobre el nivel educativo de la población para medir el grado de segregación residencial socioeconómica - presenta hallazgos relevantes. Esta investigación da indicios sobre (i) la tendencia a la localización espacial, (ii) la conformación homogénea de las zonas residenciales, es decir su característica composición social, y (iii) las percepciones subjetivas sobre la segregación objetiva. De estas destaca la tendencia a la conformación de áreas socialmente homogéneas, para las cuales encuentra correlación con un grupo poblacional particular (de acuerdo a los datos de base del estudio, se habla de la población con estudios universitarios completos) que muestran una "disposición a autosegregarse y conformar áreas fuertemente homogéneas hacia el interior” (Sánchez, 2017).

Por otra parte, Suárez y López (2015), en su investigación sobre el fenómeno de la segregación socio-residencial en Managua entre 1972-2012, presentan un análisis cuyo encuadre teórico les permitió identificar los patrones y tendencias del fenómeno en la ciudad. Identifican una transformación en el patrón tradicional de la segregación, marcada por las grandes obras de infraestructura y el crecimiento del "conjunto cerrado" como tipología constructiva (podemos decir mejor 'residencial') que ahora se desarrollan en zonas anteriormente de baja renta, pero revalorizadas por su aparición, posiblemente por la confluencia con las grandes obras.

Estos autores concluyen así que el patrón de la segregación socio-residencial de Managua, durante el período estudiado, es caracterizado por "el surgimiento de estos espacios sociales segregados en una estructura urbana fragmentada y dispersa, producto, principalmente, de la dinámica del modelo 
económico inmobiliario y de la oferta comercial de la ciudad" (Suárez y López, 2015, p.70). De igual forma, al igual que Sánchez (2017) también identifican algunas características iniciales de la tendencia a la segregación "positiva”. Los trabajos de Sánchez (2017) y Suárez y López (2015) para el caso de Managua permiten identificar lo que Espino (2008) ha planteado para las sociedades modernas, como la "tendencia marcada hacia la segregación urbana y la constitución de vecindarios social y culturalmente homogéneos" (p.43).

En términos espaciales, en Managua el modelo de crecimiento urbano ha seguido una lógica de dispersión de baja densidad que se expande hacia las áreas suburbanas, un modelo que toma fuerza sobre todo a partir del terremoto de 1972. El patrón actual muestra una expansión urbana a lo largo de los ejes viales radiales que conectan la ciudad con los municipios aledaños, lo que Duhau y Giglia (2016) plantean como la "ciudad a lo largo de la autopista" (p.40). Estas se han convertido en ejes importantes de inversión privada para la construcción de edificios comerciales y empresariales, pero también para desarrollos habitacionales con un carácter muy marcado: las viviendas de la "clase alta" (Rodgers, 2006) (ver figura 1). Estas viviendas se contraponen, en el mercado, a la oferta de "vivienda de interés social"; y en la ciudad lo hacen frente a las unidades vecinales propias de las zonas en las que se emplazan, generando cambios en la estructura urbana existente y convirtiendo a estas últimas en espacios segregados de la misma.

De tal forma que para el período 1993- (febrero) 2018, la Alcaldía de Managua registraba alrededor de 260 proyectos habitacionales legales en el área municipal. Además, el mapa de la figura 1 muestra la tendencia de los proyectos de condominio de agruparse sobre todo en las zonas más alejadas, que se interpretan como exclusivas.

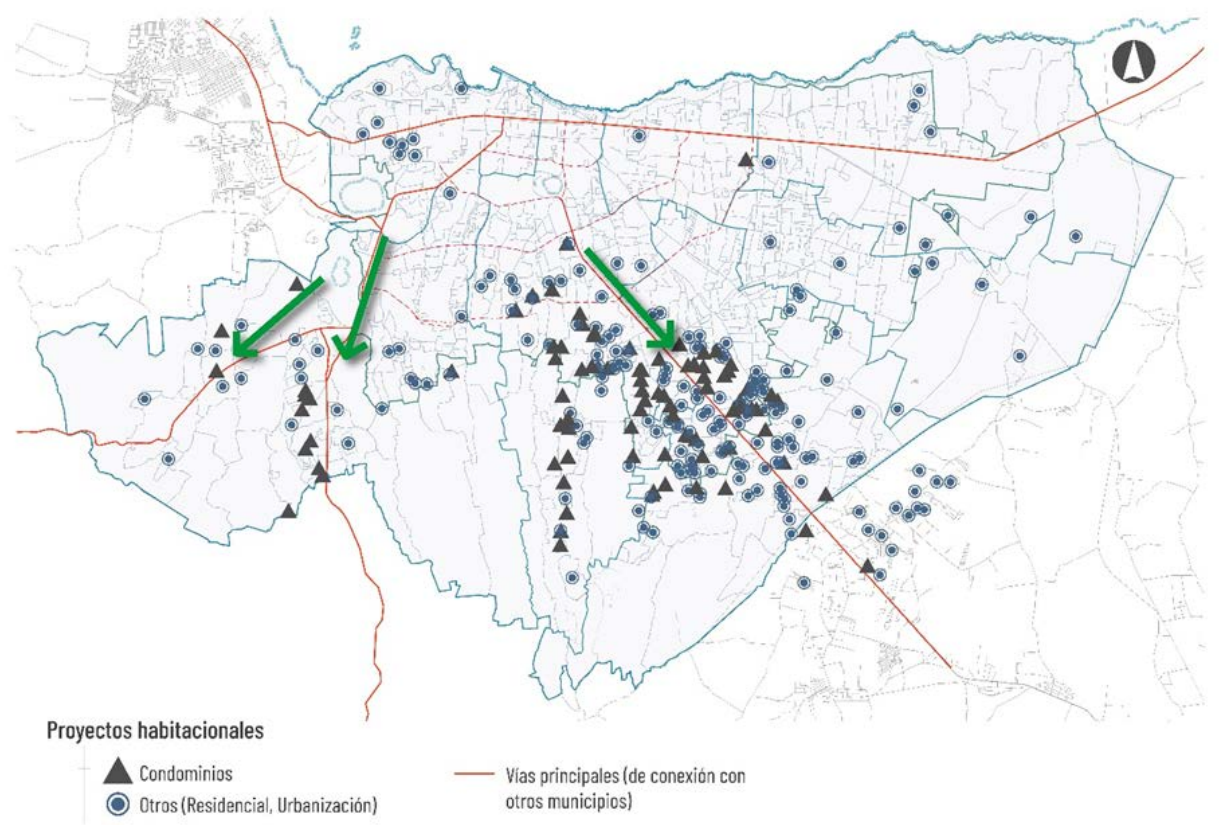

Figura 1. Ubicación de los proyectos habitacionales desarrollados entre 1998-2018. Fuente: Elaboración propia, con base a datos de ALMA (2018) y recolección de datos de oferta de proyectos habitacionales. El mapa muestra la proliferación de estos proyectos a lo largo de los ejes viales hacia el sureste y suroeste de la ciudad. 


\section{Resultados de la investigación empírica}

\section{El marco de interpretación de los resultados}

La concepción del espacio construido, en su relación con lo social, también lo constituyen en escenario de una experiencia distinta que es configurada por prácticas sociales recurrentes. Estas prácticas al ser propias de los espacios - en este caso los enclaves - representan o implican, al menos, una diferenciación de la experiencia urbana, tanto en lo social como en lo espacial. Tal como propone la corriente más culturalista de los estudios de Louis Wirth, entender el urbanismo como modo de vida debe comprender la estructura física, el sistema de organización social y el conjunto de actitudes de los habitantes.

Estas actitudes son, para autores como Simmel, distintas de aquellas conocidas en otros espacios, mientras que la ciudad es el espacio de interacciones sociales particulares, y por ello es en sí una forma de sociabilidad. El modelo de convivencia normado que tiene lugar en los enclaves parece afirmar el postulado de Simmel, aunque en unos niveles de interacción más atomizados en este nuevo modelo de ciudad.

Ahora bien, el fenómeno de la segregación urbana desde el enfoque más crítico de los estudios neo-marxistas sobre la ciudad, se aborda desde la perspectiva de la desigualdad social que se refleja en la ocupación del suelo y en la conformación de patrones de segregación (Espino, 2008). Esta va a expresar de forma espacial la distancia social entre los individuos o grupos, es decir, la espacialización de las diferencias sociales. La segregación es, entonces, una tendencia a "la organización del espacio en zonas de fuerte homogeneidad social interna y de fuerte disparidad social entre ellas" (Castells, 1991, p.204) cuya su característica definitoria es, sobre todo, el establecimiento de una jerarquía entre las zonas resultantes. Aunque la tendencia en el debate en torno a la segregación se suele plantear desde la exclusión, existe también interés por el estudio de los casos, que, al otro extremo del espectro, centran la atención en los procesos de conformación de áreas urbanas privadas "en los cuales queda materializada la distancia social" (Formiga, 2000, p.33). Dentro de la discusión que existe alrededor de nombrar a ambos procesos como "segregación", Formiga (2000) propone comprender estos últimos como procesos de "agregación", debido a su marcado carácter voluntario de aislamiento.

Para Caldeira, los instrumentos de propagación del nuevo modelo de segregación urbana en las ciudades son precisamente, lo que ella ha denominado, el 'enclave fortificado' (Caldeira, 2000 citada en Roitman, 2010), que como proyecto inmobiliario se concibe desde su diseño afirmando la segmentación social a través de los mecanismos ya citados. Estos pueden ser proyectos de desarrollo urbano de distintas tipologías, destacando los espacios comerciales o de recreación, así como los espacios residenciales diseñados bajo esta lógica; aunque también se pueden identificar equipamientos que comparten este carácter segregativo y sirven en términos de servicios a los espacios residenciales.

En acuerdo con los planteamientos más reconocidos sobre la segregación como agregación homogénea a lo interno y diferenciación a lo externo, Formiga (2000) rescata la importancia del reconocimiento de las características diferenciales, tanto desde el interior, como desde el exterior, en este caso del enclave residencial. Es decir, la agregación de un grupo homogéneo, que en teoría se segrega de un "afuera" heterogéneo se refuerza a través de la diferenciación de los espacios y la jerarquización de los mismos. Un proceso a través del cual "lo que alcanza significación social 
es la concurrencia de determinadas situaciones sociales y una localización particular en el espacio (Formiga, 2000, p.31).

Este trabajo adopta el termino propuesto por Caldeira, con una connotación de espacio residencial, así vamos a hablar de enclaves 'residenciales' o 'habitacionales' permitiendo dar cabida a la amplitud de tipologías que estos proyectos presentan en Managua. Sin embargo, por su pertinencia al preguntarse por la racionalidad de la acción de decidir habitar en un espacio como este, el concepto que vamos a tener del enclave es el propuesto por Roitman (2010), quien los define como:

Closed urban residential settlements voluntarily occupied by a homogeneous social group, where public space has been privatized by restricting access through the implementation of security devices. Gated communities are conceived as closed settlements from their inception and are designed with the intention of providing security to their residents and prevent penetration by non-residents; their houses are of high quality and have services and amenities that can be used only by their residents, who pay regular compulsory maintenance fees. They have a private governing body that enforces internal rules concerning behaviour and construction.

[Los asentamientos urbano-habitacionales cerrados voluntariamente, ocupados por un grupo social homogéneo, donde el espacio público ha sido privatizado a través de la restricción del acceso, implementando dispositivos de seguridad. Las urbanizaciones cerradas [enclaves habitacionales], son concebidas como asentamientos cerrados desde su concepción y son diseñados con la intención de proveer seguridad a sus residentes y de prevenir la entrada a no-residentes; sus casas son de alta calidad y sus servicios y amenidades solamente pueden ser usados por los residentes (...)] (Roitman, 2010, p.33).

De tal forma que para los fines de esta investigación se consideran como enclaves habitacionales auto-segregados aquellos proyectos de vivienda caracterizados por su exclusividad de uso habitacional, o por ausencia de usos mixtos (como servicios, comercios, etc.), con tipología de vivienda unifamiliar, y que han sido concebidos desde su proyección como separados de la estructura urbana de la ciudad a través de muros perimetrales, y que cuentan con al menos un tipo de barrera física, y control de acceso.

\section{¿Cómo es la vida en condominio? El nuevo modelo de convivencia}

Una de las características particulares del condominio o de los enclaves, como oferta habitacional, es la conformación de un estatuto legal del régimen de la propiedad, y de una normativa interna propia. Duhau y Giglia (2008) aseguran que los proyectos de este tipo ofrecen:

(...) una suerte de libertad controlada, posible a partir de la implementación de reglas propias, que van desde la prohibición de hacer sonar el claxon o de rebasar cierto límite de velocidad, hasta la de pintar la reja del jardín de un color distinto al establecido, o de levantar una barda (p.409).

Así, las reglas establecidas no sólo aplican al aspecto físico construido de las viviendas, sino que establecen normativas de comportamiento explícitas, creando una suerte de convivencia normada, que deja afuera la espontaneidad y los peligros percibidos en la ciudad abierta. 


\section{Acuerdo previo y gestión interna}

La gestión que tiene lugar en un condominio, al ser compartida, reduce los costos a nivel de familia, mientras les asegura poder tener cierto nivel de comodidad, dado por el mantenimiento de las condiciones de seguridad, del mantenimiento estético de los espacios compartidos y del acceso a las amenidades que ofrece el condominio. Aunque tal vez lo más importante de estos acuerdos que se establecen como reglamentos de convivencia sea el carácter prohibitivo con el que se pretende asegurar ciertas condiciones, que, sin embargo, es percibido por como positivo en tanto constriñe a todos por igual:

Pero para mí, yo lo veo como una ventaja porque también... prohíbe... que te convirtás en otra cosa, como veterinario, o tienda, o consultorio. En un condominio no podés hacer eso, que en un residencial sí lo podrías hacer. Que hay gente que compra casas y la vuelve pulpería, la vuelve salón de belleza, lo vuelve consultorio... entonces, eso no le gusta a la gente.

En el condominio hay reglamentos. es como más estricto en ese sentido, pero para el beneficio, al final, del cliente. Y eso les gusta, que saben de qué aquí no va a haber nada de eso, y que se tienen que cumplir ciertas reglas y que nadie puede cambiar la fachada de su casa. Y el asegurar la cuota de mantenimiento del condominio también aseguras que todas las áreas sociales, las áreas verdes estén bien cuidadas, que no se vea como abandonado (F. González, comunicación personal, 26 de enero, 2020).

Estas condiciones de (i) control del uso, con énfasis en la exclusividad de lo habitacional, (ii) mantenimiento de la estética de las viviendas y de los usos comunes, además de otras, las han encontrado las familias en sus distintos enclaves y han significado para ellos ya sea la aceptación de normas intransigentes en pro de un beneficio común percibido o la posible negociación de condiciones en renuncia a otras.

\section{Seguridad y control: convivencia normada}

Para asegurar el cumplimiento, existen las juntas de vecinos. Desde estas se gestionan los recursos económicos para los pagos que se hacen en colectivo, como la jardinería, la seguridad y el sistema de cámaras. Las percepciones sobre la necesidad de crear un reglamento que pudiera normar aspectos tan específicos de la convivencia demuestran, tal como plantean Duhau y Giglia (2008), como "la existencia de una reglamentación interior - eficaz y respetada - es parte del atractivo de estos espacios, en la medida en que el respeto de las reglas es un bien escaso en el espacio exterior" (p.409), es decir, en la ciudad abierta.

Al considerar la finalidad de estas directivas, Diego - uno de los entrevistados para esta investigación - considera que la finalidad última de estas sería asegurar las condiciones de convivencia entre los vecinos (aunque cabe destacar que la reglamentación varia en términos de los aspectos que regula y qué tan estricta es la regulación entre uno y otro proyecto):

Digamos actividades. Las actividades que quieras hacer en casa club, tienen que definirse las horas, los tiempos, cómo solicitar los permisos. Los pagos de las cuotas que se tienen que hacer. Los procedimientos de operar en el propio condominio. En fin, muchas tareas, muchas cosas que ayudan a mantener la relación entre todos los vecinos (D. Ulloa, comunicación personal, 02 de febrero, 2020). 
Este caso es también muy ilustrativo cómo toman forma estas normativas, en los sentidos más estrictos, incluso sobre lo que se considera como la propiedad privada de cada vivienda. Diego y su familia proyectaron construir un acceso vehicular más amplio para su casa, y atendiendo a la normativa de informar sobre este tipo de acciones, sometieron el proyecto a revisión. De la junta directiva recibieron una respuesta negativa, por lo que la ampliación no se pudo realizar. Aunque sí bien la respuesta al proyecto fue negativa, Diego y su familia entienden que, en este espacio, lo más importante es acatar las normas que han sido acordadas de previo y que se perciben como la condición que les asegura a ellos que viven en una zona tranquila, segura, sin conflictos entre los vecinos.

Para Duhau y Giglia (2008) el respeto a lo normado respecto a las características formales y estéticas de la vivienda, puede entenderse más como un mecanismo para "subrayar una supuesta homogeneidad de sus habitantes y destacar sobre todo la existencia de un orden específico" (p.409), que se dimensiona en otros niveles de control y orden.

Es relevante que en todos los casos - sin importar sí están inscritos como condominio o no, o las características de las viviendas o de los residentes - existe una condición invariable, que hace alusión a este orden específico que se busca y que, además, es muy bien percibida por todos los entrevistados: una exclusividad del uso habitacional. Diego lo explica muy concisamente:

Esas son propiedades para vivienda... [...] No se puede poner ningún negocio ni nada de eso. Y eso es muy positivo. [...] Porque realmente, de pronto, deja de ser condominio y se vuelve, no sé... un residencial. Porque la posibilidad de que los propios habitantes del condominio adquieran productos en ese lugar va a ser mínima y la persona que tiene el negocio necesariamente a va comercializarlo y a promulgarlo, y cuando miras estarían entrando personas que no son del condominio, sino que llegan solamente a comprar al minisúper. Entonces pierde la visión de un condominio (D. Ulloa, comunicación personal, 02 de febrero, 2020).

Estas percepciones que tienen sobre el control se entienden desde la propuesta de Bellet (2007) de cómo ese control del entorno que parece "aportar cierta sensación de seguridad y al menos garantiza "que tus vecinos son como tú y quieren lo mismo que tú'” (p.3), que sería en este caso, no sólo una composición social homogénea sino también una exclusividad del uso que mantiene fuera de los límites del enclave a cualquier extraño. Sin embargo, la búsqueda de esta homogeneidad, que pareciera apuntar a la búsqueda de pares con los cuáles compartir espacios, queda meramente en una apariencia de comunidad, que no se traduce en relaciones de vecindad o comunidad. Duhau y Giglia (2008), sobre el aspecto de las relaciones vecinales dentro de los enclaves, explican:

El representarse como una comunidad no es más que eso, una representación, a la que no corresponde un tejido de relaciones y de prácticas compartidas, salvo (...) las que tienen que ver con la administración de los espacios y bienes comunes (p.407).

Los casos también demuestran la validez del argumento de estos autores, desde distintos matices y percepciones sobre lo que son las relaciones de vecindad a lo interno de un enclave, que en todos los casos se ven reducidas a relaciones de cordialidad, de encuentros esporádicos y cortos en espacios de tránsito o de reuniones de comité. Es esta organización, que autores como Musa Vargas (2008) han identificado como una nueva normatividad a lo interno, la que define en gran medida la vida cotidiana - al menos en las actividades que tienen lugar en la vivienda - y de cómo 
se relaciona el enclave como el exterior, o sea, con el resto de la ciudad.

\section{Hola y adiós}

Sí algo distingue al individuo metropolitano para Simmel es la forma de socialización funcional que este implementa dentro de la organización urbana tan compleja. Para este teórico esta individualidad propia de estos sujetos conjugaba intelectualidad, predominio de la racionalidad y una actitud blasé. Esta una especie de barrera, con la que el individuo se protege de la experiencia que representa la ciudad, con su constante cambio y estímulo.

Esta premisa parece tomar gran relevancia en contextos como los que representan las ciudades hoy. No sólo exponencialmente más cambiantes que aquellas que estudió Simmel, sino también escenario de una cantidad de estímulos sensoriales que van desde vallas publicitarias digitales hasta el incrementado tránsito vehicular inundando las calles más allá de las horas pico. Por ello, no es de extrañarse, que las personas entrevistadas describen relaciones de vecindad, que no son tales, y parecen más bien configurarse por un deseo de reducir la interacción con los otros.

Para Inés y Rodrigo, una de las cosas más relevantes que encontraron en el condominio - además de una composición social muy homogénea - es que todos los vecinos parecen compartir un estilo de vida que gira en torno a las actividades que no transcurren dentro del enclave. Lo que para ella implica también un cambio en la priorización de las relaciones vecinales. Habla sobre esa relación de cordialidad con sus vecinos, que no llega a establecerse en ningún tipo de relaciones de amistad, como una especie de acuerdo tácito:

La mayoría de los vecinos comprenden que ahí nuestra relación es de 〈Hola y adiós〉, [...] es como que entendemos ese código, de 〈Hola, hola... bye, bye〉. No nos metemos plática” (I. Molina, comunicación personal 11 de noviembre, 2019).

A esta condición alude Margulis (2002) cuando argumenta como las transformaciones que experimenta la ciudad "van diluyendo su condición de lugar de encuentro con otro y de espacio de interacción y participación" (p.534), que los trabajos de Roitman $(2004,2010)$ para el caso específico de los enclaves señalan como los impactos sociales negativos. El modelo habitacional del enclave no sólo impacta la estructura y el tejido urbano de la ciudad, sino que implica cambios en las prácticas sociales y las relaciones vecinales tradicionalmente asociadas a la ciudad.

\section{Cerca, pero no tanto}

Felicia, Emilio y sus tres hijos viven en una casa de 5 habitaciones, piscina y jardín que forma parte de un enclave de sólo tres viviendas. Por ello, la gestión compartida de su espacio toma una forma menos explícita, y sólo se centra en la administración de los espacios comunes, que en su caso se limitan a la calle única que da acceso al condominio. Este enclave de tres casas, es además particular en que se encuentra dentro de un residencial más grande que ya de por sí cuenta con control de acceso y seguridad privada.

La pareja se consideran los vecinos más dinámicos, en términos de entrar y salir del espacio, tanto por su rutina de trabajo como por las actividades de los niños, sobre todo frente a la situación de tener como vecinos a una pareja que vive con su hija adolescente y se mantienen fuera todo el día, y la tercera vivienda que permanece desocupada durante los días de semana. Por ello, al momento de encarar gestiones como el mantenimiento del portón de acceso la pareja no ha tenido 
inconvenientes en asumir la responsabilidad de asegurar su funcionamiento, y no implica para los vecinos el tener que pensar en una gestión compartida, Emilio lo explica:

Organizamos todo y si les toca aportar algo, se les dice 'Mira, hicimos algo...', les preguntamos y ellos dicen 'Bueno, miren, cada vez que ustedes hagan algo, nos avisan y les pagamos' (E. Salinas, comunicación personal, 29 de octubre, 2019).

De tal forma que no existe una coordinación o arreglo explicito para el manejo interno de los espacios. Cada uno asegura el cuido de su vivienda y sus jardines de manera individual; mientras que aquellos elementos que se deben asegurar de forma colectiva (mantenimiento del portón de acceso, de la calle y de las luminarias exteriores) se traducen no en una gestión comunitaria o compartida sino en la asunción de cuotas para gastos, en la modalidad que explica Emilio, pues de hecho no cuentan con una junta de vecinos.

No sorprende que, al hablar sobre sus relaciones vecinales a lo interno del enclave, Emilio cuente que tanto él como su esposa mantienen relaciones de cordialidad con sus vecinos, y al igual que los casos anteriores, no considere tener relación de amistad con ellos. Sin embargo, hacen hincapié en cómo la configuración del enclave influye en la percepción y la conciencia de tener a estos vecinos tan cerca, e incluso de configurar o modificar ciertos comportamientos en relación a esta convivencia:

Pero lo único que tenés es que a veces... depende a veces, es la cercanía de las casas. Las casas van seguiditas, entonces ahí lo que tenés es que si tenés un pleito en la casa todos los vecinos lo escuchan. Si tenés una fiesta y hay mucha bulla... No somos así, pasa digamos que tenés cuidado porque perjudicas más al vecino porque ahí no hay muros. Es decir, los muros son pequeños, no hay tantos.

Esa cercanía te hace que todo lo que hagas pueda repercutir también al vecino. [...] tenés que tener cuidado que si los niños invaden la otra casa, que si les molesta, que si no les molesta, esa es la parte que si tenés que tener mucho cuidado. (F. Salinas, comunicación personal, 29 de octubre, 2019).

Para la pareja la configuración de esta convivencia particular dentro del enclave les parece implicar una diferencia entre la relación del "adentro" con el "afuera", frente a las relaciones a lo interno. Aunque siempre es bien valorada la seguridad, en tanto restricciones y control de accesos de afuera hacia adentro, una vez dentro del enclave, Felicia valora la convivencia desde el aspecto de la privacidad:

Es privacidad en relación al exterior, pero también tenés mucha gente cerca. Ahorita por el momento tenemos buenos vecinos. Entonces eso te permite más tranquilidad... pero de repente si tenés gente que es más bulliciosa... otro tipo de actividades que se den, también las tenés cerca. Y se dan como más cuenta de todo lo que pueda pasar en tu casa (F. Salinas, comunicación personal, 29 de octubre, 2019).

Diego, después de 9 años fuera del país llega a Nicaragua y se instala con su familia en un condominio. La realidad socio-cultural diferente y el habitar en una torre de apartamentos son el punto de comparación más reciente que tiene presente al momento de caracterizar el modo de vida del condominio. Igual, comparando con la experiencia previa de vivir en barrios y residenciales 'abiertos' de Managua. Esta suerte de importación de un modelo es lo que Bellet (2007) apunta 
como la definición de un estilo de vida globalizado que es idealizado a partir de "las imágenes de los desarrollos residenciales privados de la suburbia americana [que] ha impregnado con fuerza los gustos y pautas del consumidor" (p.2). Así, la delimitación del "adentro" y "afuera", el distanciamiento y la convivencia normada, de esto que Diego ha descrito como el "estilo de vida americanizado" dentro de los enclaves, remiten a la perspectiva de Díaz y Hernández (2009), sobre como los conjuntos de vivienda se han transformado, y ahora en la modalidad de enclaves:

[Dejan] de lado la existencia de espacios públicos, andadores y lugares para socializar, a cambios se han propuesto esquemas cerrados, restrictivos y altamente segregadoras, los cuales promuevan soluciones específicas para la ciudad contemporánea; extraterritorial, globalizada e informatizada. La vivienda de lujo se erige (...) no sólo imaginada sino añorada y representada por sectores sociales, ataviados por el concepto del "buen vivir" (p.784).

Aunque los casos también demuestran - tal como plantean Duhau y Giglia (2008) - que el modo de vida del enclave, caracterizado por su relativa tranquilidad, su seguridad controlada, también conlleva costos en la calidad de vida cotidiana. En estos casos ha implicado tanto el cuido constante del comportamiento propio a razón de no molestar al vecino, como el acatamiento de normas que incluso controlan lo que es privado de la propiedad. Lo que estos mismos autores han planteado como un modo de vida que se estructura alrededor de prácticas controladas y homogeneidad interna, de la mano con la desvinculación del entorno.

La agregación de las características socio-espaciales de los enclaves, tanto en su conformación social homogénea como su control normativo para la convivencia, son los elementos que sin duda representan un estilo de vida, que es particular en tanto implica una diferenciación a lo que se concibe tradicionalmente como el estilo de vida de las ciudades.

En estos espacios, las prácticas cotidianas de la familia, en lo que respecta a sus relaciones vecinales adquieren otros matices en tanto no pueden ser eludidas, pero siempre se ven limitadas; y por otra parte, la creación y definición de un límite como frontera respecto al exterior, que como elemento físico que representa una intención, les permite "[presumirse] ajenos al desastres citadino del exterior y [se presentan] como salvación al naufragio del caos urbano" (Díaz y Hernández, 2009, p.784). Para el caso de Managua, Suárez y López (2015) han señalado como esta configuración de los límites toma forma a partir de dos características básicas de los enclaves: "los muros perimetrales y la creación de su propia trama desvinculada de la ya existente" (p.44).

\section{Conclusiones}

Seguridad, control, gestión, son los aspectos más importantes sobre los cuales se perciben diferencias en relación a la experiencia en la ciudad abierta, y por tanto se han convertido - tanto en su expresión físico-espacial, como en la social - en objeto de una evaluación diferencial, que deviene en una diferenciación de la experiencia urbana-habitacional.

Al iniciar este trabajo, con antecedentes cómo el de Sánchez (2017) que da luces a la conformación de zonas residenciales homogéneas, la tendencia a una determinada localización espacial y a las valoraciones positivas de la segregación objetiva; y el trabajo de Suárez y López (2015) quienes ya señalaban ciertas características del patrón de segregación socio-residencial en la ciudad, y cómo se hace del fenómeno una valoración positiva y funcional; esta investigación va a sumar a estos trabajos algunas ideas esenciales de este fenómeno, explorado desde la perspectiva del enclave como posibilidad positiva, desde la perspectiva de los residentes. 
Sí bien es indispensable cierto nivel económico como condición posibilitadora para acceder a estos espacios, existen una serie de expectativas y preferencias de orden más socio-cultural para buscarlos. Estas expectativas y preferencias están mediadas por una percepción generalizada de la ciudad, y de lo que el condominio ofrece como posibilidad de una experiencia diferenciada y valorada positivamente.

Este proceso de evaluación y valoración es, desde una perspectiva de análisis micro-objetiva, una acción racional. Constituida como tal en tanto pone en relación los recursos con los que se cuenta (económicos como de conocimientos), y los deseos y expectativas de las familias. La evaluación simultanea de las condiciones convierte al enclave en oportunidad de conjugar de la mejor manera los elementos en juego.

A un nivel personal estas expectativas y preferencias están determinadas también por las características del núcleo familiar, pero se conforman, además, desde las condiciones objetivas de un contexto social que determina un orden de los valores alrededor del espacio habitacional. Este último es posible analizarlo en la construcción de los mensajes que acompañan la aparición de los enclaves como espacios urbanos; presentándolos como el escenario de un determinado estilo de vida, un estilo de vida deseado. Así, las imágenes publicitarias se convierten en dispositivo de producción de sentido y valoración de los entornos urbanos. Lo cual apunta a procesos más amplios de la configuración de los modelos de ciudad actuales.

Así, las preferencias producidas en condiciones objetivas y las racionalidades determinadas por condiciones sociales convierten a las características de estos espacios en elementos atractores, constituidos como tal en oposición a los elementos negativos percibidos en la ciudad, que terminan "expulsando" a los habitantes del tejido urbano de la ciudad hacia el enclave, en este caso, habitacional.

Las familias de los casos aquí estudiados han podido conjugar sus expectativas y preferencias con los recursos y conocimientos con los que juegan, evaluando la posibilidad de vivir en un enclave como una oportunidad que les permite obtener lo que desean. Lo que trae a colación la capacidad de acción del individuo, que, desde una posición económica ventajosa, conjuga elementos y las condiciones a su disposición en la búsqueda de las características ideales que se le adjudican al espacio habitacional

En la búsqueda de concretar en el espacio la experiencia de vida idealizada en el enclave como una posibilidad positiva, la experiencia de vivir en estos espacios se centra alrededor de la seguridad, el control y la homogeneidad como aspectos esenciales de la misma. Para el caso particular de Managua, la experiencia del enclave como tal, está determinada por la conformación de los estatutos normativos que regulan la convivencia, y aseguran así, el mantenimiento de los aspectos ya mencionados.

Las condiciones de la convivencia normada dentro del enclave se convierten en los mecanismos impositivos que asegura un orden claro dentro del espacios - al menos desde la valoración que hacen los residentes - en el que el "adentro" tiene ventajas en relación al "afuera". Estas reglas claramente establecidas no sólo aplican al aspecto físico de las viviendas y los espacios comunes, sino que establecen normativas de comportamiento explícitas, creando una suerte de convivencia normada, que deja afuera la espontaneidad y los peligros percibidos en la ciudad abierta. La posibilidad de normar aspectos tan específicos es una característica importante dentro de los enclaves, pues hace 
explicito la capacidad de controlar y ordenar el entorno y las relaciones con otros. Así, el enclave se constituye no sólo como un modelo del espacio residencial, sino también como modelo de gestión y convivencia.

Mientras seguridad se traduce en control y restricción, dentro de estos espacios también las relaciones sociales sufren cambios; la vecindad se reduce a cordialidad y la privacidad se relativiza en el esquema de convivencia con el fin de asegurar a todos los beneficios del modelo idealizado. El cuido constante del comportamiento propio a razón de no molestar al vecino, como el acatamiento de normas que incluso controlan lo que es privado de la propiedad, son algunos de los costos de la calidad de vida cotidiana tranquila y segura del enclave. De esta manera, las condiciones que asegura el modelo particular deben ser encontradas también en la disposición a renunciar o negociar unos aspectos por otros; como el control de la vivienda como propiedad privada para conservar el respaldo del enclave como una unidad de gestión, o a la calidad de relaciones vecinales en pro de una seguridad garantizada por el control y el distanciamiento. Es entonces que se puede observar cómo - aunque sea de manera incipiente - las condiciones sociales (en este caso también normativas) comienzan a generar o alterar las prácticas de sus residentes.

Sin embargo, a modo general, el enclave como posibilidad positiva es bien valorado por todas las personas entrevistadas. En el proceso de evaluación la valoración de los enclaves como espacios habitacionales, se tiene como referencia las experiencias anteriores - en todos estos casos espacios barrios tradicionales de la ciudad abierta $-\mathrm{y}$ se hace en relación a aspectos de seguridad, privacidad y vecindad.

Estas experiencias como los marcos que permiten dar valor al enclave en relación a otras, refuerzan por contraste los beneficios percibidos del modelo. En el imaginario se presentan como la materialización del ideal residencial, mientras que sus dispositivos socio-espaciales dan forma a las prácticas cotidianas que resultan en la apropiación y valoración diferencial de los mismos. Se les están constantemente atribuyendo sentido y significado. Incluso llegando a ocurrir que la vivienda no se concibe como patrimonio o proyecto de vida, sino más bien como escenario de la misma, y se valora en cada momento de la trayectoria familiar para evaluar su aptitud como ese espacio.

Tal como propone la literatura, reducir el fenómeno de los enclaves auto-segregados, y en este caso particularmente los de tipo habitacional, a aspectos de seguridad no permite ver la complejidad del fenómeno, en tanto da cuenta de procesos de formación de expectativas y preferencias colectivas, que a su vez apuntan a procesos más amplios de la conformación de las ciudades y sus dinámicas sociales y económicas. El modelo habitacional de los enclaves se relaciona con otros procesos, como la construcción de espacios y equipamientos que comparten su carácter excluyente, pero también con otros de orden económico y político como la búsqueda de una eficiencia de servicios que la ciudad y el orden público no son capaces de proveer, la búsqueda de entornos que sean más homogéneos en su composición social.

Estas preferencias creadas en contextos de condiciones objetivas, también deben estudiar desde perspectivas más macro-sociológicas, no con la intención de dejar fuera la experiencia urbana más personal, sino para poder relacionar unas con otras, dentro de procesos que a través de prácticas recurrentes y valoraciones subjetivas van reafirmando condiciones objetivas, y en los que no existe un determinismo de uno sobre el otro. 


\section{Discusión más allá de los resultados: Sugerencias para investigaciones posteriores}

Los resultados de esta investigación también dan apertura a la discusión de otras cuestiones, que no eran el centro de interés en este trabajo en particular, pero que pueden constituir líneas de investigación interesantes.

Sin duda la primera es la necesidad de crear una discusión alrededor de la cuestión de la vivienda. Estas se han constituido - desde la oferta del mercado inmobiliario - como objetos mercantilizados, sobre los cuales se construyen ideales de su forma y el estilo de vida que los acompaña. La configuración de lo residencial desde este discurso, tiene dos implicaciones, importantes cada uno por su propio derecho, pero que juntas se conjugan en patrones y procesos de transformación que crean en la ciudad discontinuidad espacial y segregación social:

\section{La exclusividad de lo habitacional como un uso que no es compatible con otros.}

Desde la práctica urbanística este modelo es propio de la concepción funcional de la ciudad, que la ordena en zonas clasificadas por el uso y las actividades preponderantes en las mismas. La reducción de la compatibilidad del uso habitacional con otros, como el comercial, el institucional, el recreativo, está creando, irónicamente, ciudades disfuncionales. Los centros de trabajo se ven vacíos durante los fines de semana, los institucionales durante la noche, y los espacios de la ciudad parece no concatenar ni tener continuidad en las prácticas de uso de sus habitantes.

\section{La exclusividad de lo habitacional como espacio social homogéneo.}

Ambas refuerzan el modelo de estructuración de las ciudades "desde arriba", un modelo que se impone, en una suerte de orden figura-fondo. Los enclaves - de todo tipo, no sólo lo habitacionales - constituyen las figuras, los espacios en los que ocurre la vida urbana, con todos sus posibles beneficios, tanto espaciales como sociales (los espacios bien equipados, con infraestructura de servicios, los espacios donde viven la población que se constituye en ciudadanía); mientras que todo lo que va quedando fuera del modelo ideal es un fondo, es en la imagen, un negativo, donde sólo queda lo que no es. Un parámetro que también se va aplicando a las personas que son "permitidas" o deseadas en los espacios.

La segunda discusión debe girar en torno a la configuración de la ciudad - que desde las teorías de la segregación urbana - toma forma desde un modelo impuesto o que viene "desde arriba". Alrededor de esta también es necesario discutir, para el caso de Managua, como esta es, además, ordenamiento avalado desde lo normativo. Por lo cual es necesario evaluar su impacto.

Estas primeras dos cuestiones también se articulan entre sí en la discusión sobre los actores que dan forma a la ciudad. Sí bien sólo se consideró a modo de contexto de la discusión de los objetivos de esta investigación, queda claro que los desarrolladores inmobiliarios juegan un papel protagónico en la creación física de la ciudad, pero también en la valoración que se hace de ella. Cuestión que incluso termina haciendo incidencia en aspectos como los valores del suelo y la vivienda, la distribución de la inversión en infraestructuras y servicios, y otros.

Por último, aunque no menos importante, sería de interés para el caso de Managua poner atención a los procesos de desterritorialización de la experiencia urbana, habilitada por los servicios de conectividad, propios de la era de la globalización, y que los nuevos servicios de mensajería - que 
ahora incluyen la entrega de comida, el encargo de compras, etc. - van creando entre los espacios de habitación, como en este caso, conectividades no físicas con los espacios y servicios, ya sea de trabajo, ocio y comercio, por nombrar algunos. En Managua, la red de archipiélagos funcionales conectados por grandes proyectos viales, que señalaba Denis Rodgers, toma otra dimensión.

\section{Referencias bibliográficas}

Álvarez-Gayou, J. (2003). Cómo hacer investigación cualitativa. Paidós: Ecuador

Bellet, C. (2007). Los espacios residenciales de tipo privativo y la construcción de la nueva ciudad: visiones de privatopía. Revista Electrónica de Geografía y Ciencias Sociales, Vol. XI, núm. 245 (08). Disponible en http://www.ub.edu/geocrit/sn/sn-24508.htm

Castells, M. (1991). La cuestión urbana. México, D.F.: Siglo Veintiuno

Díaz, V. \& Hernández, C. (2009). Imaginarios habitacionales de la vivienda de lujo frente a la globalización: El caso de la ciudad de Guadalajara. Estrategias de transformación y gestión de la ciudad; perspectivas y nuevas tecnologías. Lleva a cabo en Quinta Conferencia Internacional Ciudad y Territorio Virtual, Barcelona 2-4 junio [87]. Disponible en https:// upcommons.upc.edu/handle/2099/11943

Duhau, E. \& Giglia, A. (2008). Las reglas del desorden: habitar la metrópoli. Siglo XXI: México.

Duhau, E., \& Giglia, A. (2016). Metrópoli, espacio público y consumo (1ra ed.). México: Fondo de Cultura Económica.

Espino, A. (2008). La segregación urbana: Una breve revisión teórica para urbanistas. Revista de Arquitectura, 10, 34-47. ISSN: 1657-0308. Disponible en: https:/www.redalyc.org/ pdf/1251/125112541006.pdf

Formiga, E. (2000). La diferenciación socioespacial y los espacios subjetivos de los bahienses (Tesis doctoral). Universidad Complutense de Madrid, España. Disponible en: https://eprints. ucm.es/2529/

Janoschka, M. (2002). El nuevo modelo de la ciudad latinoamericana: fragmentación y privatización. Revista eure (Vol. XXVIII, No 85), pp. 11-29, Santiago de Chile, diciembre.

Janoschka, M. \& Glasze, G. (2003). Urbanizaciones cerradas: un modelo analítico. Ciudades, N59, pp.9-20.

López, N. (2016). Urbanización desigual en la ciudad de Managua, de 1995 a 2015 (documento de trabajo). Recuperado de http://biblioteca.clacso.edu.ar/clacso/becas/20160331030347/ Informe.pdf

Rodgers, D. (2006). Desimbricando la ciudad: crimen, inseguridad y organización espacial en Managua, Nicaragua. Encuentro. (73), 8-24.

Roitman, S. (2010). Gated communities: definitions, causes and consequences. Institution of Civil Engineers. pp.31-38.

Roitman, S. (2004). Urbanizaciones cerradas: estado de la cuestión hoy y propuesta teórica. Revista 
de Geografía Norte Grande (35), 5-19.

Roitman, S. (2003). Barrios cerrados y segregación social urbana. Scripta Nova Revista Electrónica de Geografía y Ciencias Sociales, VII (146;118). Disponible en http://www.ub.edu/geocrit/ sn/sn-146(118).htm

Sánchez, P. (2017, octubre). Patrón y tendencias de la segregación residencial socioeconómica en la ciudad de Managua. IX Foro de Hábitat Popular: Derecho a la Ciudad y Producción Social del Hábitat, presentado en Universidad Centroamericana UCA, Managua. [diapositivas de PowerPoint].

Suárez, B. \& López, N. (2015). Segregación socio-residencial en la ciudad de Managua - Cuaderno de Investigación 30. Managua: UCA Publicaciones. 